(c) American Dairy Science Association, 2007.

\title{
Isolation of Bovine Immunoglobulins Resistant to Peptic Digestion: New Perspectives in the Prevention of Failure in Passive Immunization of Neonatal Calves
}

\author{
A. C. R. C. Porto, ${ }^{*}$ L. L. Oliveira, ${ }^{*}$ L. C. Ferraz, ${ }^{*}$ L. E. S. Ferraz, ${ }^{*}$ S. M. O. Thomaz, ${ }^{\star}$ \\ J. C. Rosa, ${ }^{\star} \dagger$ and M. C. Roque-Barreira* \\ *Departamento de Biologia Celular e Molecular e Bioagentes Patogênicos, and \\ †Centro de Química de Proteínas, Faculdade de Medicina de Ribeirão Preto, Universidade de São Paulo, Av. Bandeirantes 3900 \\ 14049-900 Ribeirão Preto, São Paulo, Brazil
}

\begin{abstract}
In calves, neonatal mortality and disease susceptibility are greatly influenced by failure in passive immunization, normally provided by colostrum ingestion just after birth. Formulations projected to replace natural colostrum have not been successful, and one of the possible reasons for such failure is that orally administered Ig are probably digested in the gastrointestinal tract, so they are not absorbed as intact functional molecules. With the aim of finding an adequate colostrum substitute, we used columns of immobilized jacalin, a lectin known by its ability to bind $O$-linked oligosaccharides, to obtain a colostral Ig population putatively protected against enzymatic cleavage by the presence of sugar chains. Immunoglobulin $G_{1}$ is a major constituent of colostrum Ig bound to jacalin (JB-Ig). This preparation contains $10 \%$ of the total colostral Ig and is typically 3 to 6 times more resistant to pepsin digestion than the Ig contained in the fraction that is not bound to jacalin, which presumably does not contain $O$-glycans. Mass spectrometry analysis demonstrated that the tryptic peptides obtained from JB-Ig and unbound Ig were similar, indicating that their distinct susceptibility to enzyme hydrolysis was associated with differences in their sugar chains. Therefore, the present research suggests that the bovine colostrum JB-Ig has potential application in the immunotherapy of neonatal calves that have not been supplied with colostrum.
\end{abstract}

Key words: bovine colostrum, immunoglobulin, jacalin, peptic digestion

\section{INTRODUCTION}

Colostrum ingestion is the natural process that most significantly confers efficient immune protection to neo-

Received June 13, 2006.

Accepted September 18, 2006.

${ }^{1}$ Corresponding author: mcrbarre@fmrp.usp.br natal calves during their initial life stage, when they are agammaglobulinemic (Robison et al., 1988). This condition is a consequence of the absence of Ig transplacental passage, which is characteristic of the bovine species. In fact, calves have immature innate defense mechanisms and no specific immunity at birth. Therefore, passive immunization is crucial and can be provided by ingestion of colostrum containing high levels of Ig. Dairy cattle colostrum contains 3 Ig isotypes, G, $\mathrm{M}$, and A, which respectively account for about 85 to 90,5 , and $7 \%$ of the total Ig concentration (DeveryPocius and Larson, 1983). The colostrum volume and its Ig concentration are largely dependent on the breed, parity, and duration of the nonlactating period of cows (Pritchett et al., 1991). Effective immunity transfer via colostrum ingestion also depends on the ability of the neonate to ingest and absorb the ingested Ig.

Absorption of intact large proteins by the intestine of the newborn occurs only within the first $24 \mathrm{~h}$ of life (Matte et al., 1982), when IgG becomes increasingly detectable in the calf's blood. Low IgG plasma concentrations are directly related to calf morbidity and mortality (Besser and Gay, 1994), as well as to impairment of the calf's long-term performance (Wittum and Perino, 1995). Plasma IgG concentrations lower than $10 \mathrm{mg} /$ $\mathrm{mL}$, extended for 24 to $48 \mathrm{~h}$ after birth, indicate failure in passive transfer (Bovine Alliance on Management and Nutrition, 1995; Arthington et al., 2000).

Colostrum supplement products have been developed and used as a source of exogenous Ig for calves. Preparations alternative to natural colostrum have been the object of several studies in which the use of concentrated milk whey (Mee et al., 1996), dried colostrum (Morin et al., 1997), and an injectable Ig solution (Quigley and Welborn, 1996) have been proposed. In general, these preparations have not conferred passive immunity to calves (Mee et al., 1996; Morin et al., 1997).

The major human colostrum Ig, IgA $\mathrm{A}_{1}$, can be detected or isolated on the basis of its binding to jacalin, a lectin from Artocarpus integrifolia (Roque-Barreira and

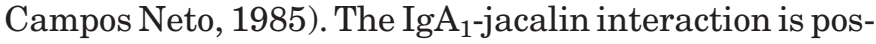


sible because of the lectin recognition of $O$-glycans associated with the $\operatorname{Ig} \mathrm{A}_{1}$ hinge region. The presence of jacalin-binding $O$-glycans accounts for the $\operatorname{IgA}_{1}$ resistance to hydrolysis by the gastrointestinal tract proteases (Kim et al., 1994; Van den Steen et al., 1998), whose access to the peptide backbone is blocked (Jentoft, 1990). Several mammalian Ig have $O$-linked glycans, and this is also true for an important part of the Ig molecules present in the bovine colostrum. Therefore, we have taken advantage of the binding of some Ig molecules to jacalin to isolate such $O$-glycosylated Ig and to demonstrate its increased resistance to pepsin digestion, compared with the bovine colostrum Ig not bound to jacalin.

\section{MATERIALS AND METHODS}

\section{Bovine Colostrum}

Bovine colostrum was obtained from 10 different multiparous cows, 3 to $6 \mathrm{yr}$ old, raised on a local dairy farm, fed with an adequate ration and corn silage. A pool of these samples was delipidated following centrifugation at $490 \times \mathrm{g}$, at $4^{\circ} \mathrm{C}$, for $1 \mathrm{~h}$. After being diluted (vol/vol) in $0.15 \mathrm{M} \mathrm{NaCl}$, the material was acidified with glacial acetic acid to adjust the $\mathrm{pH}$ to 4.6 , and the solution was centrifuged at $17,400 \times g$ for $15 \mathrm{~min}$ to remove $\mathrm{CN}$. Finally, the $\mathrm{pH}$ of the obtained colostral whey was raised to 7.2 with $10 \mathrm{~m} M$ PBS.

To separate the $\gamma$-globulin fraction, colostral whey was precipitated with $50 \%$ ( $\mathrm{vol} / \mathrm{vol}$ ) saturated ammonium sulfate and centrifuged at $12,000 \times g$, at $4^{\circ} \mathrm{C}$, for $10 \mathrm{~min}$. The resulting whey was then dissolved in PBS. This procedure was repeated twice. Ammonium sulfate was removed using an ultradiafiltration system (Amicon Division, W.R. Grace \& Co., Beverly, MA). The protein concentration of the final preparation was determined (Lowry et al., 1951).

\section{Fractionation of Colostral Whey Through Affinity to Immobilized Jacalin}

The Ig-enriched colostral whey was affinity chromatographed on a jacalin-agarose column operated at $4^{\circ} \mathrm{C}$, according to a previously described protocol (Roque-Barreira and Campos Neto, 1985). Briefly, the starting material ( $2 \mathrm{~mL}$ containing $18 \mathrm{mg}$ of protein) was loaded onto the column (5-mL bed) and the unbound material, eluted with PBS, constituted a preparation termed jacalin-not bound Ig (NB-Ig). Following exhaustive washing of the column with PBS, the bound fraction, termed jacalin-bound Ig (JB-Ig), was eluted with 0.4 $M$ D-galactose and dialyzed against PBS. Protein concentrations of both preparations were determined (Lowry et al., 1951) using BSA as the standard.

\section{JB-Ig Isotyping}

The $\mathrm{IgG}_{1}, \mathrm{IgG}_{2}, \mathrm{IgM}$, and IgA concentrations in JBIg were determined by using a bovine ELISA quantitation kit (Bethyl Laboratories Inc., Montgomery, TX), according to the manufacturer's instructions.

\section{Pepsin Digestion}

The JB-Ig and NB-Ig (15 $\mu \mathrm{g}$ of dried protein) were individually resuspended in $10 \mu \mathrm{L}$ of $0.1 \mathrm{M}$ sodium acetate, $\mathrm{pH}$ 4.0. Pepsin (1 mg/mL; Sigma Chemical Co., St. Louis, MO), diluted in $0.1 M$ acetate buffer, $\mathrm{pH}$ 4.0, was then added to the sample, providing a pepsinsubstrate ratio of 1:30. The reaction was incubated at $37^{\circ} \mathrm{C}$ and stopped by raising the $\mathrm{pH}$ to 8.6 through addition of $10 \mu \mathrm{L}$ of $3 M$ Tris-HCl. All samples were kept at the same final volume $(20 \mu \mathrm{L})$.

\section{SDS-PAGE and Western Blot}

Sodium dodecyl sulfate-PAGE was performed by the method of Laemmli (1970) under nonreducing (10\% polyacrylamide gel) or reducing conditions ( $12.5 \%$ polyacrylamide gel) using a Mini-Protean 3 electrophoresis cell (Bio-Rad Laboratories, Inc., Richmond, CA), according to the manufacturer's instructions. Samples were prepared in $63 \mathrm{~m} M$ Tris- $\mathrm{HCl}$ sample buffer, $\mathrm{pH}$ 6.8 , containing $2 \%$ SDS and $10 \%$ glycerol, either in the presence or in the absence of $2 \% 2$-mercaptoethanol. All the runs were performed at $200 \mathrm{~V}$ and protein bands were stained with Coomassie brilliant blue R-250 (Amersham Biosciences Corp., Piscataway, NJ). Prestained standards (Bio-Rad Laboratories, Inc.) were used to estimate the molecular weight of the sample proteins. The intensity of the protein band staining was measured by using SigmaGel image analysis software (Sigma Chemical Co.).

To perform Western blot analyses, proteins separated by SDS-PAGE were electroblotted onto nitrocellulose membranes (Hybond-C Extra; Amersham Biosciences) by means of a Minigel system (Bio-Rad), according to the manufacturer's instructions. After transfer, the nitrocellulose sheets were blocked with PBS containing $3 \%$ gelatin and $0.05 \%$ Tween 20 at room temperature, for $1 \mathrm{~h}$. After being washed 3 times with PBS supplemented with $0.05 \%$ Tween 20 , the membranes were incubated with biotinylated antibovine IgG (Pierce Chemical Co., Rockford, IL) or biotinylated jacalin for 1 h. After a new cycle of washings with PBS, the reacting bands were developed with streptavidin-alkaline phosphatase conjugate (Calbiochem-Novabiochem Co., La Jolla, CA) and nitroblue tetrazolium chloride-5-bromo4-chloro-3-indolyl phosphate (NBT/BCIP; Sigma). Precision prestained standards (Bio-Rad) were used to esti- 
mate the molecular weight of the antibody and the lectin-recognized bands.

\section{Mass Spectrometry Analysis of the IgG Peptides}

Peptides obtained via trypsin and pepsin hydrolysis of the JB-Ig and NB-Ig were desalted in a microTip filled with POROS R2 (PerSeptive Biosystems, Foster City, CA) and eluted in 60\% methanol and 5\% formic acid for mass spectrometry (MS) analysis, carried out in a Quattro II electrospray triple-quadrupole mass spectrometer (Micromass, Manchester, UK) by direct infusion $(300 \mathrm{~nL} / \mathrm{min})$ under the following conditions: capillary voltage maintained at $2.8 \mathrm{kV}$, cone voltage at $40 \mathrm{~V}$, and cone temperature set to $100^{\circ} \mathrm{C}$. The parameters for MS scanning were optimized with synthetic peptide for the highest signal-to-noise ratio, and the mass was calibrated with polyethylene glycol. Spectra were collected as the average of 10 to 30 scans ( 2 to 5 s/scan) and processed using MassLynx v. 3.3 software (Micromass).

\section{RESULTS}

\section{Isolation and Characterization of JB-Ig}

Bovine colostrum was delipidated, decaseinated, and precipitated with ammonium sulfate to obtain an Igenriched colostral whey preparation. Fractionation of the colostral whey proteins was performed by affinity chromatography on an immobilized jacalin column. By loading the jacalin-agarose column (5-mL bed) with 18 $\mathrm{mg}$ of whey proteins, $1.5 \mathrm{mg}$ of the bound protein was eluted with a $0.4 M$ D-galactose solution. This yield was subsequently reproducible in several similar procedures and yielded homogeneous Ig preparations (JBIg), according to the criteria of the SDS-PAGE analysis, carried out in both reducing and nonreducing conditions (Figure 1). Nonreduced samples exhibited a largely prominent $180-\mathrm{kDa}$ protein band (Figure 1A) coincident with that of bovine IgG (Tizard, 1998). Reduced samples provided bands of apparent molecular mass of about 60 and about $30 \mathrm{kDa}$ (Figure 1B), a profile compatible with heavy and light Ig chains. This interpretation was reinforced by the observation that, in a Western blot assay, the $60-$ and $30-\mathrm{kDa}$ bands were developed by goat antibodies specific to bovine IgG (Figure 1C). The Western blot analysis of the reduced samples also showed that biotinylated jacalin developed the $60-\mathrm{kDa}$ band only, suggesting that $O$-glycans recognized by jacalin are associated with the heavy chain of the isolated bovine IgG (Figure 1D). This indicated that $O$-glycosylation was predominantly associated with the heavy chain of the bovine colostral antibodies.

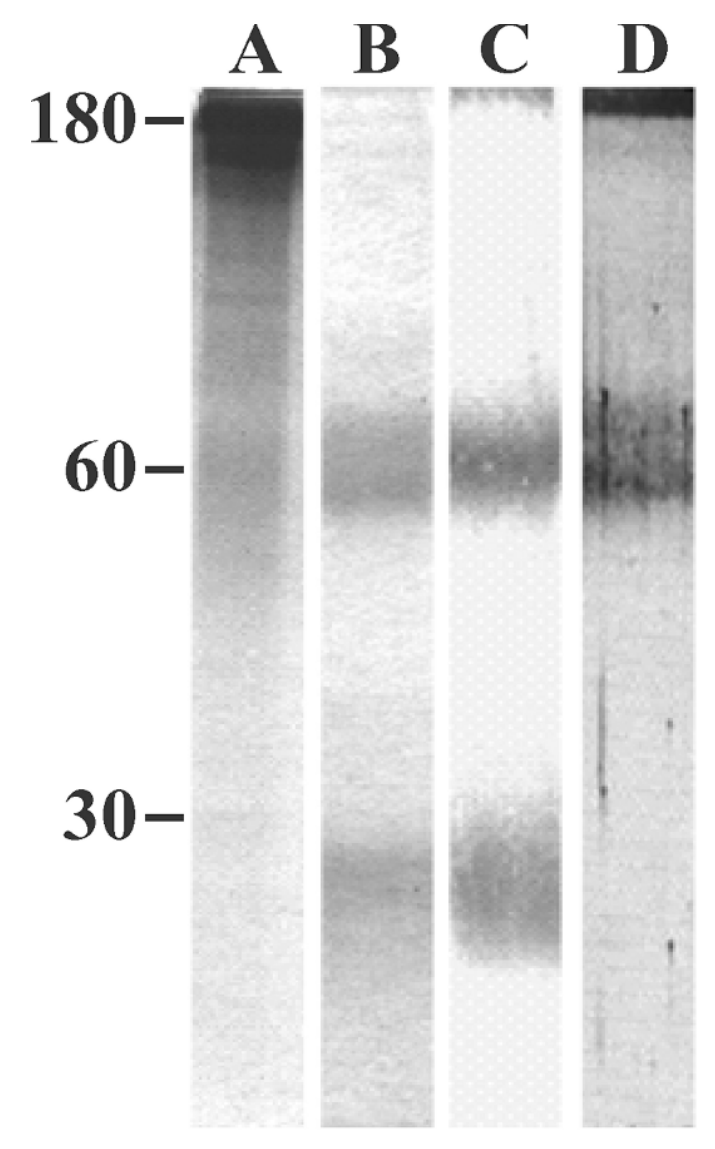

Figure 1. Characterization of the jacalin-bound Ig (JB-Ig) by SDSPAGE and Western blot. Samples of JB-Ig were submitted to SDSPAGE under nonreducing (A) and reducing (B) conditions to evaluate the homogeneity of the JB-Ig fraction. The JB-Ig under reducing conditions was blotted onto nitrocellulose membrane and revealed with antibovine IgG or jacalin. The heavy and light chains reacted with antibovine $\operatorname{IgG}(\mathrm{C})$, whereas only the heavy chain was recognized by jacalin (D).

Isotyping of JB-Ig (Table 1) showed that more than $80 \%$ of the total Ig corresponded to $\mathrm{IgG}_{1}$, whereas the other Ig were distributed into the M $(9.6 \%), \mathrm{A}(6 \%)$, and $\mathrm{G}_{2}(0.9 \%)$ isotypes.

\section{Ig Characterization by MS Analysis of Tryptic Peptides}

The peptide mass fingerprints, determined by electrospray ionization-MS, resulting after the tryptic diges-

Table 1. Jacalin-bound colostral Ig isotyping

\begin{tabular}{lcc}
\hline Isotype & $\begin{array}{l}\text { Concentration } \\
\text { of } \mathrm{Ig}, \mu \mathrm{g} / \mathrm{mL}\end{array}$ & $\%$ of total Ig \\
\hline IgG $_{1}$ & 342.0 & 83.4 \\
IgG $_{2}$ & 3.7 & 0.9 \\
IgM & 39.5 & 9.7 \\
IgA & 24.9 & 6.0 \\
Total & 410.1 & 100 \\
\hline
\end{tabular}


tion of JB-Ig and NB-Ig, were compared. The coincident peptide mass fingerprints of the 2 preparations indicate that distinctions between JB-Ig and NB-Ig did not concern their peptide backbone (data not shown).

\section{Determination by SDS-PAGE and Western Blot of JB-Ig Resistance to Pepsin Digestion}

To evaluate whether $O$-glycosylation of the bovine Ig would provide resistance to peptic digestion, the JB-Ig and NB-Ig preparations were reacted with pepsin at $\mathrm{pH} 4.0$, at an enzyme-to-antibody ratio of 1:30. The electrophoretic profile of the resulting digest was kinetically analyzed, and NB-Ig was clearly demonstrated to undergo a faster and more drastic digestion compared with JB-Ig. The SDS-PAGE of the digested JBIg in nonreducing conditions showed that the detection of a $180-\mathrm{kDa}$ band corresponding to intact IgG still persisted after 120 min of reaction, whereas in the case of NB-Ig, fading away of the intact IgG occurred after 20 min of reaction (Figure 2A). Figure 2B makes the faster NB-Ig digestion even more evident. The heavy chain $(60 \mathrm{kDa})$ of NB-Ig was extensively digested by pepsin in $20 \mathrm{~min}$, in contrast with the persistence of this band in the case of JB-Ig. A densitometry analysis of the gel containing the reduced samples showed that $89.3 \%$ of NB-Ig was digested in the first 30 min of reaction, whereas only $45.5 \%$ of JB-Ig was digested during this same period (data not shown).

Western blot analysis developed with antibody specific to bovine IgG showed that all the NB-Ig heavy chain was digested within 30 min of enzymatic reaction, in contrast with the persistent detection of the $60-\mathrm{kDa}$ band in the case of the JB-Ig samples, even after 120 min of reaction (Figure 3). This result reinforced the idea that JB-Ig is resistant to peptic digestion.

\section{Determination of JB-Ig Resistance to Pepsin Digestion by Electrospray Ionization-MS}

The optimal conditions for peptic hydrolysis were determined by enzymatic reaction with native and heatdenaturated horse myoglobin. Analysis by MS (data not shown), using an enzyme-to-substrate ratio of 1:30, revealed an adequate profile when the reaction was developed for $4 \mathrm{~h}$ at $37^{\circ} \mathrm{C}$ in $0.1 \mathrm{M}$ sodium acetate buffer at $\mathrm{pH}$ 4.0. Mass spectral data obtained for horse myoglobin hydrolysis demonstrated a sequence covering of 49\% (10 peptic peptide ions representing 75 of 153 residues). There was no significant difference between the peptic peptides obtained from the native or the denaturated myoglobin (data not shown). These results validated the pepsin protease activity and the optimal experimental conditions for Ig peptic digestion.
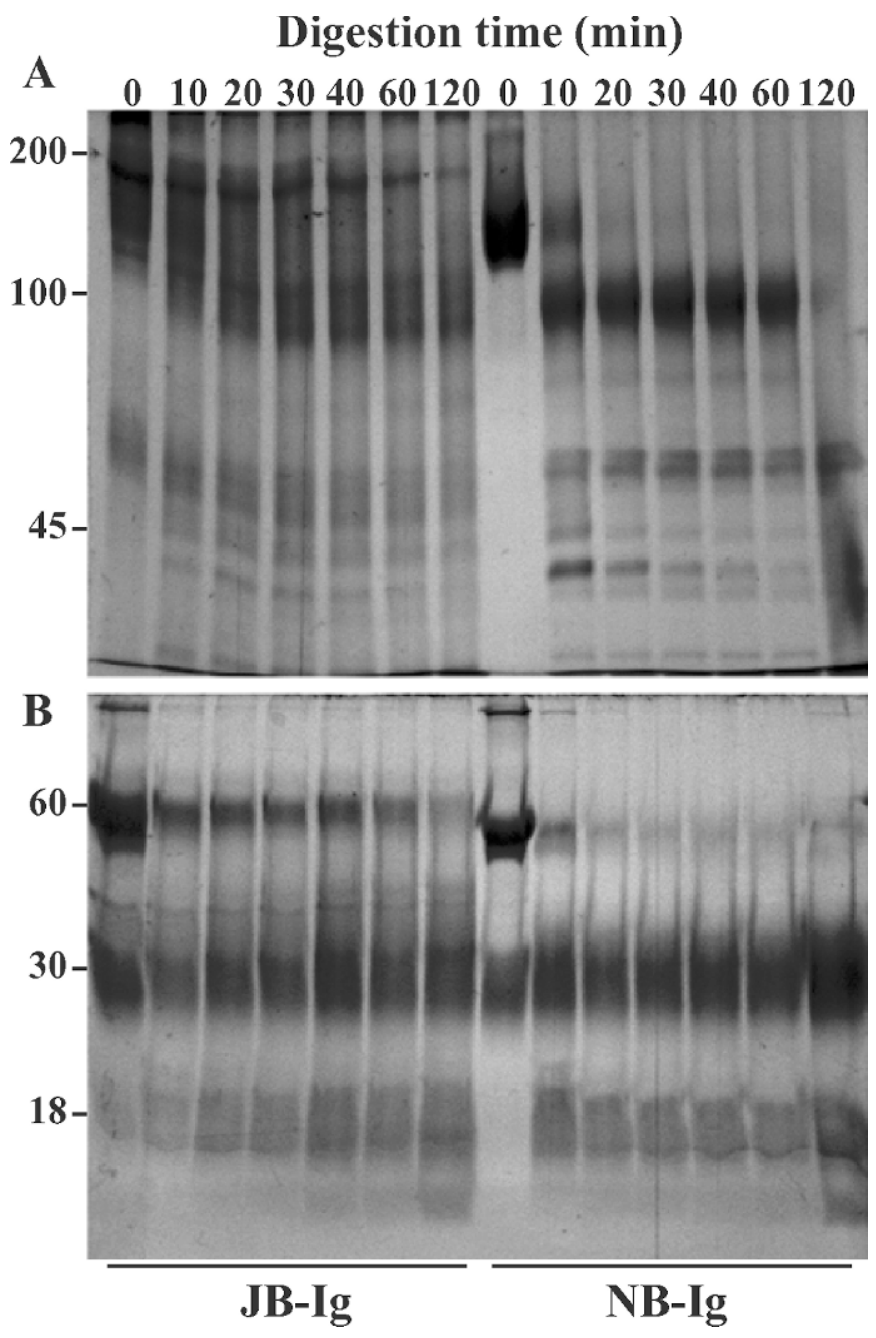

Figure 2. Time course hydrolysis of jacalin-bound (JB-) and not bound (NB-) Ig. Samples of JB-Ig and NB-Ig were treated with pepsin for different periods of time to compare the kinetics of protein degradation. The materials derived from the reaction were examined by SDS-PAGE in nonreducing (panel A) or reducing (panel B) conditions.

The JB-Ig and NB-Ig preparations were submitted to 4,8 , and $24 \mathrm{~h}$ of hydrolysis with pepsin, and the peptic peptides were detected by MS. Figures $4 \mathrm{~A}$ and $4 \mathrm{~B}$ show the MS results provided by samples after $4 \mathrm{~h}$ of hydrolysis. In the mass spectra, the intensity of 4 peptide ions at $m / z 523,578,629$, and 728 was used to estimate Ig resistance to pepsin hydrolysis (Figure 4C). To circumvent the possible differences in the proton transfer ionization of these peptide ions that were effectively transferred into the gas phase, the intensity of the peaks at $m / z 523,578,629$, and 728 obtained after 4,8 , and $24 \mathrm{~h}$ of hydrolysis provided a direct comparison. On the basis of the intensity ratio obtained for the peptide ions of both the JB-Ig and NB-Ig samples, we estimated that JB-Ig was at least 6 times more resistant 


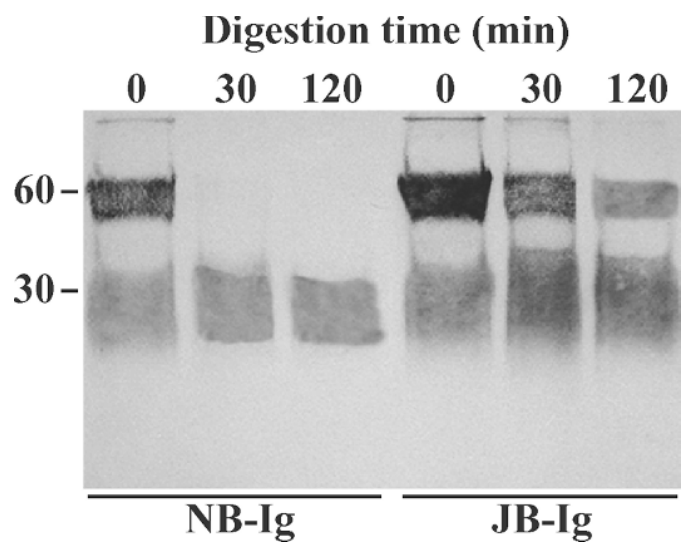

Figure 3. Time course hydrolysis of jacalin-bound (JB-) and not bound (NB-) Ig. Samples of NB-Ig and JB-Ig were treated with pepsin at several time points, separated by SDS-PAGE in reducing conditions, and electroblotted onto nitrocellulose. Western blot was revealed with antibovine IgG. Observe that the NB-Ig fraction (left) is less resistant to digestion than the JB-Ig fraction (right).

to pepsin hydrolysis than was NB-Ig. Mass measurement of the ions generated by pepsin digestion of JBIg, including the 4 mentioned above, demonstrated that they matched the peptides from the bovine IgG molecule, as detailed in Table 2.

\section{DISCUSSION}

Colostrum is vital for the health and survival of neonatal calves, and $18 \%$ of dairy cows provide colostrum yields containing less than $100 \mathrm{~g}$ of IgG, the most commonly recommended amount to prevent failure in passive transfer (Levieux and Ollier, 1999). Failure in passive transfer is correlated with disease susceptibility, economic loss, a negative impact on future production, and mortality among dairy cows. To enhance the poor protection provided by ingestion of colostrum in low volumes or of colostrum containing low Ig levels, the use of colostrum replacement products has been proposed. However, results have been mediocre, a fact essentially attributed to the poor absorption of intact Ig by the calves' intestines (Mee et al., 1996; Morin et al., 1997). A number of studies have highlighted the putative requirement of a colostrum factor able to enhance Ig absorption, which has been preliminarily characterized as a low molecular weight protein (Bush and Staley, 1980) absent from the milk (Michanek et al., 1990). Devenport et al. (2000) observed that the addition of other proteins had little effect on the absorption of IgG in neonatal calves. Quigley et al. (2001) suggested that the fractionation of bovine plasma to manufacture a colostrum supplement influenced the absorption of Ig.

Immunoglobulin A is the only protein of human colostrum that is able to bind to jacalin (Roque-Barreira and
Campos Neto, 1985). This is because the lectin is able to recognize $O$-glycans associated with the hinge region of the IgA $\alpha 1$ chain (Skea et al., 1988). This binding property has made jacalin a useful tool for isolating several $O$-glycosylated proteins, such as human $\mathrm{C}-1$ inhibitor, human plasminogen, human chorionic gonadotropin, and bovine coagulation factor X (Hortin and Trimpe, 1990). In the case of human IgA, the presence of $O$-glycans is associated with resistance to enzymatic digestion, a very suitable property for a protein that is released in the gastrointestinal tract lumen. We have therefore hypothesized that other mammalian secretory Ig could contain glyco-structures similar to those presented by human IgA, and that such Ig glycoforms could share the human IgA functional property of resistance to enzyme digestion. For practical reasons discussed above, we focused the investigation of our hypothesis on bovine colostrum Ig.

This study showed that IgG binds to jacalin in bovine colostrum. Indeed, preferential binding occurs with $\operatorname{IgG}_{1}$, which is the predominant Ig class in colostrum, representing $85 \%$ of the total Ig (Larson et al., 1980). Jaster (2005) has already highlighted the importance of colostral $\mathrm{IgG}_{1}$ intake and absorption by neonates.

The Western blot analysis of reduced JB-Ig showed that biotinylated jacalin detected the $60-\mathrm{kDa}$ band only. This suggests that, as in the case of human IgA (Baenziger and Kornfeld, 1974; Yoo and Morrison, 2005), $O$ glycans are associated with the heavy chain in bovine IgG.

The ability of newborn calf intestinal cells to endocytose macromolecules, including Ig, and to transport these intact molecules across the epithelium into the bloodstream ceases within the first day after birth through a process known as "intestinal closure." In addition to the maturation of the intestinal cells, the secretion of digestive enzymes may also contribute to determining lower levels of plasma Ig in calves, because Ig degradation may occur before its absorption (Quigley and Drewry, 1998). At birth and for a limited period thereafter, the secretion of digestive enzymes remains limited, allowing macromolecules such as IgG to escape digestion. However, some studies have demonstrated that the presence of relatively high levels of pepsin in the stomach of the neonate (Guilloteau et al., 1983), which reaches its highest levels $12 \mathrm{~h}$ after birth, contributes to reduced absorption of IgG in its native form. Concerning this fact, we understand that for a formulation to confer efficient passive protection, it must contain Ig resistant to the action of the digestive enzyme, thus maximizing the absorption of these antibodies by newborn calves.

An apparent universal consequence of $O$-glycosylation is the relative resistance of the $O$-glycosylated 
A

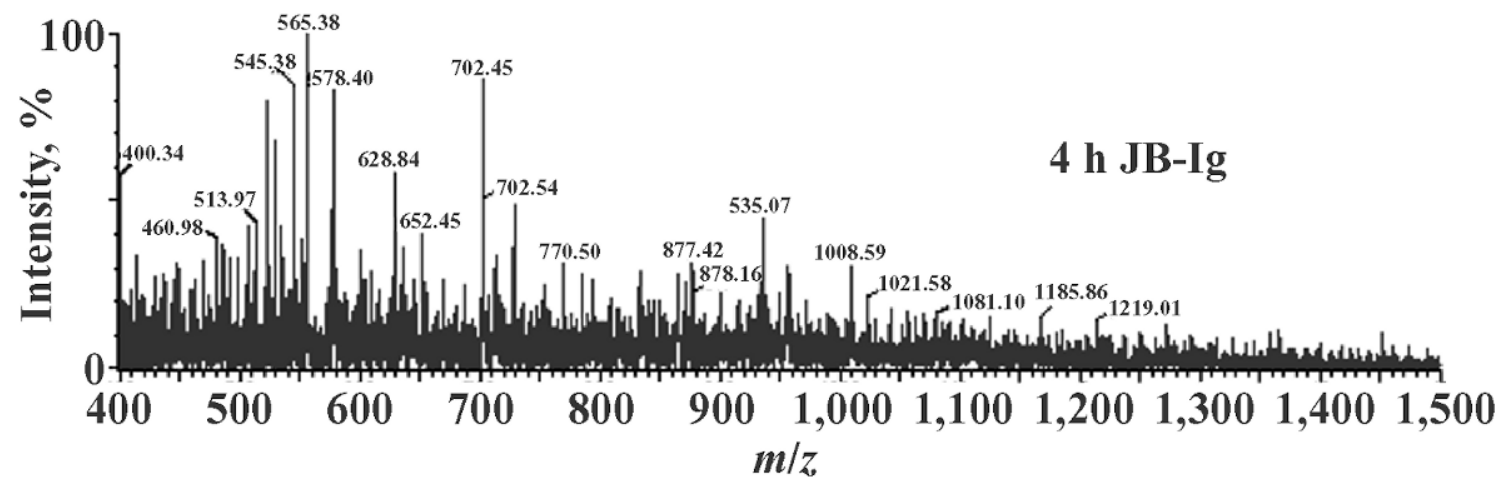

B

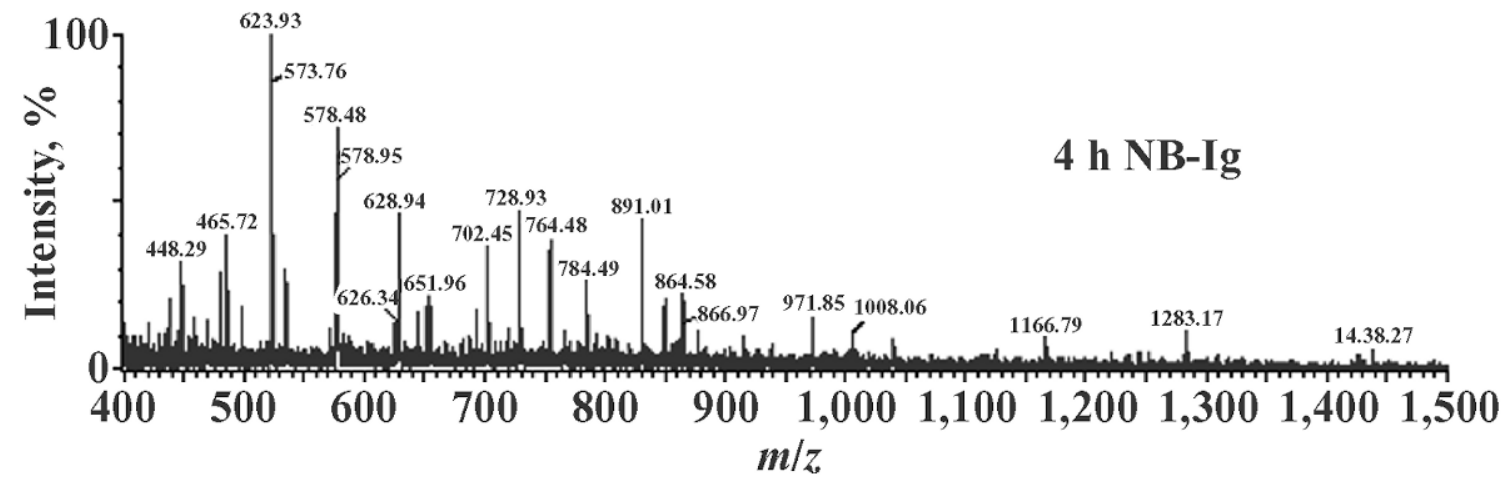

C

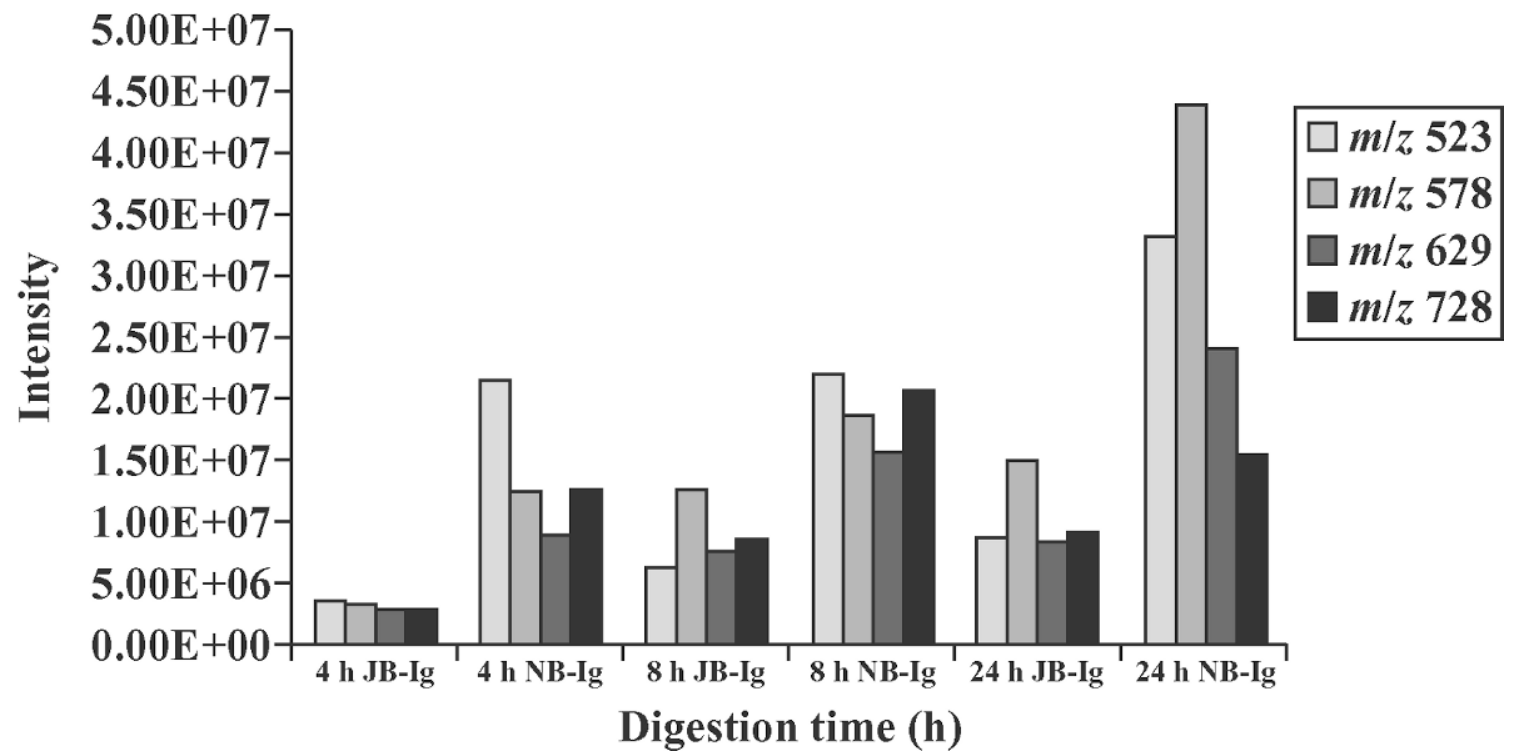

Figure 4. Pepsin hydrolysis characterization of jacalin-bound (JB-) and not bound (NB-) Ig by mass spectrometry (MS). (A) Mass spectrometry analysis of JB-Ig after $4 \mathrm{~h}$ of enzymatic reaction; (B) MS analysis of NB-Ig after $4 \mathrm{~h}$ of enzymatic reaction; and (C) comparison of peptic ions $\mathrm{m} / \mathrm{z} 523,578,629$, and 728 after 4,8 , and $24 \mathrm{~h}$ of enzymatic reaction. The NB-Ig generated more peptides than the JB-Ig. 
Table 2. Peptic peptide mass mapping of native bovine jacalin-bound $\operatorname{Ig}^{1}$

\begin{tabular}{llrll}
\hline$m / z$ & $M_{\mathrm{r}}$ & Delta $^{2}$ & \multicolumn{1}{c}{ Residues } & Sequence \\
\hline $480.4\left[\mathrm{M}+3 \mathrm{H}^{+}\right]$ & $1,436.74$ & 0.75 & $887-900$ & (F)CLVMGVLFAVDTGL \\
$523.3\left[\mathrm{M}+3 \mathrm{H}^{+}\right]$ & $1,565.79$ & 0.80 & $457-470$ & (F)KMIDNMGIPSFLAF \\
$534.7\left[\mathrm{M}+3 \mathrm{H}^{+}\right]$ & $1,601.78$ & 0.70 & $1269-1282$ & (L)TCSAFSFYPPELKL \\
$578.4\left[\mathrm{M}+2 \mathrm{H}^{+}\right]$ & $1,155.64$ & 0.65 & $1249-1258$ & (W)KEPPSMRLKA \\
$628.9\left[\mathrm{M}+2 \mathrm{H}^{+}\right]$ & $1,254.61$ & -0.18 & $868-878$ & (A)PETLQTVSSFF \\
$654.9\left[\mathrm{M}+2 \mathrm{H}^{+}\right]$ & $1,307.72$ & 0.93 & $519-529$ & (W)INVLREDHVTL \\
$702.4\left[\mathrm{M}+2 \mathrm{H}^{+}\right]$ & $1,402.77$ & 0.98 & $1041-1053$ & (W)GQGLRVTVSSMRL \\
$728.4\left[\mathrm{M}+2 \mathrm{H}^{+}\right]$ & $1,453.70$ & -0.09 & $726-738$ & (A)ARTEAENTVTYSL \\
$784.4\left[\mathrm{M}+2 \mathrm{H}^{+}\right]$ & $1,565.79$ & 0.80 & $457-470$ & (F)KNIDNMGIPSFLAF \\
$864.9\left[\mathrm{M}+2 \mathrm{H}^{+}\right]$ & $1,727.93$ & -0.06 & $770-786$ & (L)LLSADTQTADPSKAVVL \\
$971.5\left[\mathrm{M}+2 \mathrm{H}^{+}\right]$ & $1,939.96$ & 0.77 & $442-459$ & (L)DSLDSGHGKEVPPTFKNI \\
$1,283.2\left[\mathrm{M}+3 \mathrm{H}^{+}\right]$ & $3,847.37$ & -0.11 & $205-238$ & (L)SDPVQLEIHSDWLLLQVTSRVFTEGDPLALRCHA \\
$1,425.6\left[\mathrm{M}+3 \mathrm{H}^{+}\right]$ & $4,275.08$ & 0.70 & $474-510$ & (A)RRNRAHCTPWHPWGHMLLWTALLFLAPVSGKPDLPKA \\
\hline
\end{tabular}

${ }^{1}$ The site cleavage specificity of pepsin was defined as a peptide with the C-terminal portion containing the following AA: L, I, F, A, and W (source: www.proteinprospector.ucsf.edu).

${ }^{2}$ Difference of the theoretical molecular mass and experimental molecular mass determined by mass spectrometry.

regions of glycoproteins to proteases (Jentoft, 1990). It is well known, for example, that the heavy chain of mouse $\operatorname{IgG}_{2 b}$ is resistant to the attack of a variety of proteases including pepsin, papain, and elastase (Demignot et al., 1989; Kim et al., 1994), a fact that has been associated with the asymmetric $O$-glycosylation of the hinge region. Our observations demonstrate a significant difference between the resistance of JB-Ig and NB-Ig to peptic digestion. Evaluation of pepsin hydrolysis of the intact and separated chains of IgG by gel electrophoresis is consistent with the analysis of peptic peptides by MS. These data strongly suggest that the $O$-glycosylated forms of $\mathrm{Ig}$ are more resistant to enzymatic hydrolysis, even when submitted to long exposure to protease action.

A number of methods have been proposed for IgG isolation from colostrum and milk (Al-Mashikhi and Nakai, 1988; Hahn et al., 1998; Su and Chiang, 2003). However, contrary to our protocol, none of them provides the selection of more resistant Ig to gastric enzyme action. Jacalin, the substance that was the basis for the Ig separation procedure presented here, is the major protein in jackfruit seeds and is very easy to isolate. This could contribute to obtaining it inexpensively. One medium-sized jackfruit, collected from a plant that grows naturally in tropical climates, provides 25 to $30 \mathrm{~g}$ of jacalin. In addition, jacalin is a very stable lectin. By preventing contamination, we can store a dry preparation of jacalin for months, even at room temperature, with no detectable activity loss (RoqueBarreira and Campos Neto, 1985).

The goal of this work was to show that the use of affinity chromatography on a jacalin-agarose column could provide preparations rich in bovine colostrum type $1 \mathrm{IgG}$. Moreover, we demonstrated that these $\mathrm{IgG}_{1}$ preparations were highly resistant to peptic hydrolysis. We thus postulate that the ingestion of such a prepara- tion by calves should favor whole antibody absorption, as well as the transfer of adequate passive immunity to neonates.

\section{ACKNOWLEDGMENTS}

The authors thank Andrea M. B. Dalora and Bela Vista Farm for the colostrum samples. This work was supported by grants from Fundação de Amparo à Pesquisa do Estado de São Paulo, Conselho Nacional de Desenvolvimento Científico e Tecnológico, and Coordenação de Aperfeiçoamento de Pessoal de Nível Superior.

\section{REFERENCES}

Al-Mashikhi, S. A., and S. Nakai. 1988. Separation of immunoglobulin and transferrin from blood serum and plasma by metal chelate interaction chromatography. J. Dairy Sci. 71:1756-1763.

Arthington, J. D., M. B. Cattell, J. D. Quigley, III, G. C. McCoy, and W. L. Hurley. 2000. Passive immunoglobulin transfer in newborn calves fed colostrum or spray-dried serum protein alone or as supplement to colostrum of varying quality. J. Dairy Sci. 83:2834-2838.

Baenziger, J., and S. Kornfeld. 1974. Structure of the carbohydrate units of IgA $\mathrm{A}_{1}$ immunoglobulin II. Structure of $O$-glycosidically linked oligosaccharide units. J. Biol. Chem. 249:7270-7281.

Besser, T. E., and C. C. Gay. 1994. The importance of colostrums to the health of the neonatal calf. Vet. Clin. North Am. 10:107-117.

Bovine Alliance on Management and Nutrition. 1995. A Guide to Colostrum and Colostrum Management for Dairy Calves. American Feed Industry Assoc., Arlington, VA.

Bush, L. J., and T. E. Staley. 1980. Absorption of colostral immunoglobulins in newborn calves. J. Dairy Sci. 63:672-680.

Demignot, S., M. C. Garnett, and R. W. Baldwin. 1989. Mouse IgG2b monoclonal antibody fragmentation. Preparation and purification of $\mathrm{Fab}, \mathrm{Fc}$ and $\mathrm{Fab} / \mathrm{c}$ fragments. J. Immunol. Methods 121:209-217.

Devenport, D. F., J. D. Quigley, III, J. E. Martin, J. A. Holt, and J. D. Arthington. 2000. Addition of casein or whey protein to colostrum or a colostrum supplement product on absorption of IgG in neonatal calves. J. Dairy Sci. 83:2813-2819.

Devery-Pocius, J. E., and L. B. Larson. 1983. Age and previous lactations as factors in the amount of bovine colostral immunoglobulins. J. Dairy Sci. 66:221-226. 
Guilloteau, P., T. Cooring, P. Garnot, P. Martin, R. Toullec, and G. Durand. 1983. Effects of age and weaning on enzyme activities of abomasum and pancreas of the lamb. J. Dairy Sci. 66:2373-2385.

Hahn, R., P. M. Schulz, C. Schaupp, and A. Jungbauer. 1998. Bovine whey fractionation based on cation-exchange chromatography. J. Chromatogr. A. 795:227-287.

Hortin, G. L., and B. L. Trimpe. 1990. Lectin affinity chromatography of proteins bearing $O$-linked oligosaccharides: Application of jacalin agarose. Anal. Biochem. 88:271-277.

Jaster, E. H. 2005. Evaluation of quality, quantity, and timing of colostrum feeding on immunoglobulin G1 absorption in Jersey calves. J. Dairy Sci. 8:296-302.

Jentoft, N. 1990. Why are proteins $O$-glycosylated? Trends Biochem. Sci. 15:291-294.

Kim, H., Y. Yamaguchi, K. Masuda, C. Matsunaga, K. Yamamoto, T. Irimura, N. Takahashi, and K. Kato. 1994. O-Glycosylation in hinge region of mouse immunoglobulin G2b. J. Biol. Chem. 269:12345-12350.

Laemmli, U. K. 1970. Cleavage of structural proteins during the assembly of the head of bacteriophage T4. Nature 277:680-685.

Larson, B. L., H. L. Heary, Jr., and J. E. Devery. 1980. Immunoglobulin production and transport by the mammary gland. J. Dairy Sci. 63:665-671.

Levieux, D., and A. Ollier. 1999. Bovine immunoglobulin G, $\beta$-lactoglobulin, $\alpha$-lactoglobulin and serum albumin in colostrum and milk during the early post partum period. J. Dairy Res. 66:421-430.

Lowry, O. H., N. J. Rosebrough, A. L. Farr, and R. J. Randall. 1951. Protein measurement with the Folin phenol reagent. J. Biol. Chem. 193:265-275.

Matte, J. J., C. L. Girard, J. R. Seoane, and G. J. Brisson. 1982. Absorption of colostral immunoglobulin G in the newborn calf. J. Dairy Sci. 65:1765-1770.

Mee, J. F., K. J. O'Farrell, P. Reitsma, and R. Mehra. 1996. Effect of a whey protein concentrate used a colostrum substitute or supplement on calf immunity, weight gain, and health. J. Dairy Sci. 79:886-894.

Michanek, P., M. Ventorp, and B. Westrom. 1990. Milk intake before first colostrum in newborn dairy calves. Effect on intestinal transmission of macromolecules. J. Dairy Sci. 73:480-483.
Morin, D. E., G. C. McCoy, and W. L. Hurley. 1997. Effects of quality, quantity, and timing of colostrum feeding and addition of a dried colostrum supplement on immunoglobulin G1 absorption in Holstein bull calves. J. Dairy Sci. 80:747-753.

Pritchett, L. C., C. C. Gay, T. E. Besser, and D. D. Hancock. 1991. Management and production factors influencing immunoglobulin G1 concentration in colostrum from Holstein cows. J. Dairy Sci. 74:2336-2341.

Quigley, J. D. I. I. I., and J. J. Drewry. 1998. Nutrient and immunity transfer from cow to calf pre- and postcalving. J. Dairy Sci. 81:2779-2790.

Quigley, J. D., R. E. Strohbehn, C. J. Kost, and M. M. O'Brien. 2001. Formulation of colostrum supplements, colostrum replacers and acquisition of passive immunity in neonatal calves. J. Dairy Sci. 84:2059-2065.

Quigley, J. D. I. I. I., and M. G. Welborn. 1996. Influence of injectable immunoglobulin on serum immunoglobulin concentrations in dairy calves. J. Dairy Sci. 79:2032-2037.

Robison, J. D., G. H. Stott, and S. K. DeNise. 1988. Effects of passive immunity on growth and survival in the dairy heifer. J. Dairy Sci. 71:1283-1287.

Roque-Barreira, M. C., and A. Campos Neto. 1985. Jacalin: An IgAbinding lectin. J. Immunol. 134:1740-1743.

Skea, D. L., P. Christopolus, A. G. Plaut, and B. J. Underdown. 1988. Studies on the specificity of the IgA-binding lectin, jacalin. Mol. Immunol. 25:1-6.

Su, C. K., and B. H. Chiang. 2003. Extraction of immunoglobulin-G from colostral whey by reverse micelles. J. Dairy Sci. 86:16391645 .

Tizard, I. R. 1998. Imunologia Veterinária. 5th ed. Rocca, São Paulo, Brazil.

Van den Steen, P., P. M. Rudd, R. A. Dwek, and G. Opdenakker. 1998. Concepts and principles of $O$-linked glycosylation. Crit. Rev. Biochem. Mol. Biol. 33:151-208.

Wittum, T. E., and L. J. Perino. 1995. Passive immune status at post partum hour 24 and long-term health and performance of calves. Am. J. Vet. Res. 56:1149-1154.

Yoo, E. M., and S. L. Morrison. 2005. IgA: An immune glycoprotein. Clin. Immunol. 116:3-10. 